Arq. Bras. Med. Vet. Zootec., v.68, n.3, p.733-738, 2016

\title{
Lisina digestível na ração de frangos de corte tipo caipira na fase de crescimento
}

\author{
[Dietary digestible lysine in free-range broiler chickens during the growth phase] \\ R.G. Oliveira ${ }^{1}$, S.R.F. Pinheiro ${ }^{2 *}$, M.R. Castro ${ }^{1}$, L.R.A. Abreu ${ }^{1}$, A.V. Pires ${ }^{2}$, D.J. Vieira ${ }^{1}$, \\ L.F.M. Mota ${ }^{1}$, J.A. Miranda ${ }^{1}$, G.M.F. Rocha ${ }^{1}$, L.S. Costa ${ }^{3}$ \\ ${ }^{1}$ Aluno de pós-graduação - UFVJM - Diamantina, MG \\ ${ }^{2}$ Universidade Federal dos Vales do Jequitinhonha e Mucuri - UFVJM - Diamantina, MG \\ ${ }^{3}$ Aluno de graduação - UFVJM - Diamantina, MG
}

\begin{abstract}
RESUMO
O presente experimento foi conduzido para determinar as exigências de lisina digestível para frangos de corte (linhagem Redbro), machos e fêmeas, durante o período de crescimento. Foram utilizados 630 frangos, alojados em 30 boxes com acesso à área de pastejo. $\mathrm{O}$ delineamento experimental utilizado foi o inteiramente ao acaso, em esquema fatorial $5 \times 2$ (lisina e sexo), e três repetições com 21 aves cada. Os níveis de lisina digestível avaliados foram: 7,07; 8,07; 9,07; 10,07 e 11,07g/kg. Avaliou-se o consumo de lisina, o consumo de ração, o ganho de peso e a conversão alimentar. Observou-se efeito de interação $(\mathrm{P}<0,05)$ entre os níveis de lisina e sexo para o ganho de peso. Houve efeito $(\mathrm{P}<0,01)$ dos níveis de lisina sobre o consumo de lisina, o ganho de peso e a conversão alimentar. Verificou-se que todas as variáveis foram influenciadas $(\mathrm{P}<0,05)$ pelo sexo dos frangos. Recomendam-se 10,08 e 9,49g de lisina digestível $/ \mathrm{kg}$ de ração, correspondendo ao consumo estimado de 21 e $20 \mathrm{~g}$ de lisina, para machos e fêmeas, respectivamente, para melhor ganho de peso das aves. Para melhor conversão alimentar, recomendam-se 9,61g de lisina digestível/kg, para frangos de ambos os sexos, correspondendo ao consumo estimado de $20 \mathrm{~g}$ de lisina.
\end{abstract}

Palavras-chave: aminoácidos, desempenho, exigência nutricional, proteína ideal

\begin{abstract}
This experiment was conducted to determine the requirements of digestible lysine in male and female free-range broiler chickens (Redbro lineage) during the growth phase. Six hundred and thirty broiler chickens were allocated in 30 pens with access to the pasture area. The experimental design was completely randomized in a 5x2 (lysine and gender) factorial arrangement with 3 repetitions with 21 chickens each. The levels of digestible lysine evaluated were: 7.07, 8.07, 9.07, 10.07 and 11.07g/kg. The performance traits evaluated were lysine intake, feed intake, weight gain and feed conversion ratio. An interaction effect $(P<0.05)$ was observed between dietary lysine level and gender for body weight gain. There was an effect $(P<0.01)$ of the levels of lysine on lysine intake, body weight gain and feed conversion ratio. It was found that all the variables were affected $(P<0.05)$ for the gender of chickens. We recommended 10.08 and $9.49 \mathrm{~g}$ of digestible lysine $\mathrm{kg}$ diet, corresponding to the estimated intake of 21 and $20 \mathrm{~g}$ of lysine, for males and females, respectively, for better body weight gain of chickens. For better feed conversion ratio, the recommendation is of $9.61 \mathrm{~g}$ of lysine $/ \mathrm{kg}$ of diets, for chickens of both genders, corresponding to the estimated intake of $20 \mathrm{~g}$ of lysine.
\end{abstract}

Keywords: amino acids, ideal protein, nutritional requirement, performance

Recebido em 9 de fevereiro de 2015

Aceito em 15 de novembro de 2015

*Autor para correspondência (corresponding author)

E-mail: sandrafreitaspinheiro@gmail.com 


\section{INTRODUÇÃO}

A avicultura alternativa oferece produtos provenientes da criação de aves em sistema semi-intensivo, em que parte da alimentação é suprida por alimentos naturais e parte por rações balanceadas. De acordo com Albino et al. (2001), essas aves possuem características próprias e apresentam curvas e taxas de crescimento diferentes das linhagens convencionais, tendo um crescimento mais lento, logo suas exigências nutricionais podem divergir das exigências de frangos de corte convencionais.

Quando se trata de nutrição, são poucos os trabalhos sobre as reais exigências nutricionais dessas aves (Nascimento et al., 2009). Portanto, considerando que a alimentação representa o maior custo na produção animal, fornecer rações balanceadas e adotar programas nutricionais adequados à genética animal favorece não só o desempenho produtivo das aves, mas é fundamental para o retorno econômico da atividade. A partir disso, torna-se necessário conhecer as condições nutricionais para as diferentes linhagens de aves e para cada fase de criação.

A exigência de todos os aminoácidos é estimada com base em um aminoácido referência. $\mathrm{O}$ mais usado tem sido a lisina, cuja escolha é devido, principalmente, ao fato de que, em seu metabolismo, é usada quase que exclusivamente para acréscimo de proteína corporal, por ser considerada o segundo aminoácido limitante para aves, em rações compostas por milho e farelo de soja, e por ter sua exigência largamente estudada (Conhalato, 1998).

Objetivou- se com este trabalho avaliar a exigência de lisina digestível para frangos de corte tipo caipira, machos e fêmeas, da linhagem Redbro na fase de crescimento (22 a 42 dias de idade).

\section{MATERIAL E MÉTODOS}

O experimento foi realizado no Setor de Avicultura do Departamento de Zootecnia, da Universidade Federal dos Vales do Jequitinhonha e Mucuri, Diamantina, MG, para determinar as exigências de lisina digestível para frangos de corte tipo caipira, criados em semiconfinamento, na fase de crescimento (22 a 42 dias), no mês de fevereiro de 2013.

As instalações experimentais constituíam 30 boxes (área de abrigo), com acesso à área de pastejo. Cada abrigo possuía o pé-direito de $2,0 \mathrm{~m}$, coberto com telhas de fibrocimento, laterais de tela galvanizada, providas com cortinas de ráfia, piso cimentado com área de $4 \mathrm{~m}^{2}$, forrado com cama de maravalha $( \pm 5 \mathrm{~cm}$ de espessura), onde se localizava um comedouro tubular e um bebedouro tipo pendular. A área de pastejo, cercada por tela galvanizada, continha, predominantemente, gramíneas da espécie Tifton 85 , caracterizando o sistema de semiconfinamento.

Foram utilizados 630 frangos machos e fêmeas, da linhagem Redbro, com peso médio inicial de $480 \mathrm{~g}$. Os frangos foram distribuídos em delineamento inteiramente ao acaso, em esquema fatorial $5 \times 2$ (níveis de lisina $\mathrm{x}$ sexo) e três repetições, sendo cada unidade experimental constituída de 21 aves.

As aves permaneceram limitadas ao abrigo até o $27^{\circ}$ dia e, a partir do $28^{\circ}$ dia, tiveram acesso à área de pastejo, sendo soltas, diariamente, às oito horas e recolhidas para o abrigo às $18 \mathrm{~h}$.

Foi formulada uma ração basal, composta, principalmente, por milho e farelo de soja, suplementada com aminoácidos industriais para atender às exigências nutricionais das aves, com exceção da lisina (Tab. 1). Os níveis de fósforo disponível e de cálcio seguiram os recomendados por Pinheiro et al. (2011a) e Pinheiro et al. (2011b), e os demais nutrientes conforme Rostagno et al. (2011) para frangos de corte machos de desempenho regular. Os níveis de lisina digestível foram obtidos pela suplementação com L-lisina $\mathrm{HCl}, \quad \mathrm{em}$ substituição ao amido de milho e ao ácido glutâmico em equivalente proteico, sendo avaliados os níveis de 7,07; 8,07; 9,07; 10,07 e $11,07 \mathrm{~g} / \mathrm{kg}$. Para assegurar que nenhum outro aminoácido se tornasse limitante, a ração foi suplementada com aminoácidos industriais (metionina, treonina, triptofano, valina, isoleucina e arginina), conforme a necessidade, para evitar que suas relações com lisina digestível ficassem abaixo daquelas preconizadas por Rostagno et al. (2011) na proteína ideal. 
Lisina digestível na ração...

Tabela 1. Composição percentual e níveis nutricionais calculados das rações experimentais para a fase de crescimento (22 a 42 dias de idade)

\begin{tabular}{|c|c|c|c|c|c|}
\hline \multirow{2}{*}{ Ingredientes } & \multicolumn{5}{|c|}{ Lisina digestível $(\mathrm{g} / \mathrm{kg})$} \\
\hline & 7,07 & 8,07 & 9,07 & 10,07 & 11,07 \\
\hline Milho moído & 70,13 & 70,13 & 70,13 & 70,13 & 70,13 \\
\hline Farelo de soja (45\%) & 22,32 & 22,32 & 22,32 & 22,32 & 22,32 \\
\hline Fosfato bicálcico & 1,33 & 1,33 & 1,33 & 1,33 & 1,33 \\
\hline Óleo de soja & 0,01 & 0,01 & 0,01 & 0,01 & 0,01 \\
\hline Calcário calcítico & 1,24 & 1,24 & 1,24 & 1,24 & 1,24 \\
\hline Sal comum & 0,46 & 0,46 & 0,46 & 0,46 & 0,46 \\
\hline Suplemento mineral ${ }^{(1)}$ & 0,05 & 0,05 & 0,05 & 0,05 & 0,05 \\
\hline Suplemento vitamínico ${ }^{(2)}$ & 0,10 & 0,10 & 0,10 & 0,10 & 0,10 \\
\hline Amido de milho & 0,15 & 1,00 & 1,04 & 1,57 & 1,93 \\
\hline L-glutâmico (99\%) & 4,11 & 3,08 & 2,72 & 1,68 & 0,82 \\
\hline L-lisina $\mathrm{HCl}(79 \%)$ & 0,00 & 0,10 & 0,20 & 0,30 & 0,40 \\
\hline DL-metionina (99\%) & 0,06 & 0,14 & 0,21 & 0,29 & 0,36 \\
\hline L-triptofano $(99 \%)$ & 0,00 & 0,00 & 0,00 & 0,02 & 0,03 \\
\hline L-treonina $(99 \%)$ & 0,00 & 0,00 & 0,05 & 0,12 & 0,18 \\
\hline L-valina $(99 \%)$ & 0,00 & 0,00 & 0,04 & 0,11 & 0,19 \\
\hline L-isoleucina $(99 \%)$ & 0,00 & 0,00 & 0,02 & 0,09 & 0,16 \\
\hline L-arginina $(99 \%)$ & 0,00 & 0,00 & 0,04 & 0,14 & 0,25 \\
\hline Cloreto de colina $(60 \%)$ & 0,04 & 0,04 & 0,04 & 0,04 & 0,04 \\
\hline \multirow[t]{2}{*}{ Total } & 100,00 & 100,00 & 100,00 & 100,00 & 100,00 \\
\hline & \multicolumn{5}{|c|}{ Composição calculada } \\
\hline Proteína bruta $(\%)$ & 17,99 & 17,55 & 17,62 & 17,54 & 17,55 \\
\hline Energia metabolizável (kcal/kg) & 3.003 & 3.011 & 3.015 & 3.024 & 3.033 \\
\hline Cálcio (\%) & 0,88 & 0,88 & 0,88 & 0,88 & 0,88 \\
\hline Fósforo disponível (\%) & 0,35 & 0,35 & 0,35 & 0,35 & 0,35 \\
\hline Sódio $(\%)$ & 0,20 & 0,20 & 0,20 & 0,20 & 0,20 \\
\hline Lisina digestível (\%) & 0,70 & 0,80 & 0,90 & 1,00 & 1,10 \\
\hline Metionina + cistina digestível $(\%)$ & 0,52 & 0,59 & 0,66 & 0,73 & 0,81 \\
\hline Metionina digestível (\%) & 0,29 & 0,36 & 0,44 & 0,51 & 0,58 \\
\hline Treonina digestível (\%) & 0,54 & 0,54 & 0,59 & 0,65 & 0,72 \\
\hline Triptofano digestível (\%) & 0,16 & 0,16 & 0,16 & 0,18 & 0,19 \\
\hline Valina digestível (\%) & 0,67 & 0,67 & 0,71 & 0,78 & 0,86 \\
\hline Isoleucina digestível (\%) & 0,59 & 0,59 & 0,62 & 0,68 & 0,75 \\
\hline Arginina digestível (\%) & 0,95 & 0,95 & 0,98 & 1,09 & 1,19 \\
\hline
\end{tabular}

por kg do produto: manganês, $75.000 \mathrm{mg}$; ferro, $50.000 \mathrm{mg}$; zinco, $70.000 \mathrm{mg}$; cobre, $8.500 \mathrm{mg}$; cobalto, 200mg; iodo, $1.500 \mathrm{mg}$ e veículo q.s.p. $1.000 \mathrm{~g}$. ${ }^{(2)}$ por $\mathrm{kg}$ do produto: vitamina $\mathrm{A}-12.000 .000 \mathrm{UI}$, vit. D3 - 2.200.000UI, vit. $\mathrm{E}-30 \mathrm{~g}$, vit. $\mathrm{B} 1-2,2 \mathrm{~g}$, vit. $\mathrm{B} 2-6 \mathrm{~g}$, vit. $\mathrm{B} 6-3,3 \mathrm{~g}$, vit. $\mathrm{B} 12-0,016 \mathrm{mcg}$, ácido pantotênico - 13g, vit. $\mathrm{K} 3-2,5 \mathrm{~g}$, ácido fólico $-1 \mathrm{~g}$, selênio $-250 \mathrm{mg}$, antioxidante $-100.000 \mathrm{mg}$ e veículo q.s.p. $-1.000 \mathrm{~g}$.

Durante todo o período experimental, as aves receberam ração e água à vontade, e, diariamente, foram registradas as temperaturas máxima e mínima no interior das instalações às oito e às 18 horas. Quando houve mortalidade, esta foi registrada conforme a data e a parcela experimental. Não foi realizado nenhum programa de luz, as aves receberam somente luz natural.

As variáveis de desempenho avaliadas foram: consumo de ração (g/ave), consumo de lisina (g/ave), ganho de peso (g/ave) e conversão alimentar ( $\mathrm{g}$ ração consumida/g de ganho de peso). $\mathrm{O}$ consumo de ração foi calculado como a diferença entre o total de ração fornecida e as sobras, sendo corrigido pela mortalidade, quando houve. Para avaliação do ganho de peso, as aves foram pesadas no início e no final do período experimental. Com base no consumo de ração e no ganho de peso, foi calculada a conversão alimentar. 
Os dados das variáveis analisadas foram submetidos à análise de variância usando-se o procedimento GLM do sistema de análises estatísticas (SAS, 2008) para avaliar possíveis efeitos ou interação entre os fatores analisados. Quando houve efeito significativo dos níveis de lisina ou do sexo na análise de variância, foram realizadas análises de regressão, considerando-se os níveis de lisina digestível da ração como variável independente. Para verificar o ajuste dos modelos, foi considerada a soma dos quadrados dos desvios, a significância do teste $\mathrm{F}$ e os coeficientes de determinação $\left(\mathrm{R}^{2}=\mathrm{SQ}\right.$ regressão / SQ tratamentos). As estimativas dos níveis ótimos de lisina digestível foram feitas por meio dos modelos Linear Response Plateau (LRP) e polinomial quadrático e linear simples. Quando possível o ajuste simultâneo dos dois modelos, as estimativas das exigências de lisina digestível foram obtidas por meio da primeira intersecção da equação quadrática com o platô do LRP, conforme descrito por Sakomura e Rostagno (2007)

\section{RESULTADOS E DISCUSSÃO}

As temperaturas médias obtidas durante o período experimental foram $33,7^{\circ} \mathrm{C}$ (máxima) e $20,5^{\circ} \mathrm{C}$ (mínima). De acordo com Oliveira et al. (2006), a temperatura ambiente para frangos de corte deve estar em $32^{\circ} \mathrm{C}$ no primeiro dia, reduzindo, gradativamente, até atingir $21^{\circ} \mathrm{C}$ aos 49 dias de idade. É sabido que frangos de corte de pescoço pelado apresentam maior resistência ao calor, pois eles são capazes de dissipar mais calor, em razão da redução de até $40 \%$ na plumagem, de forma que devem ser preferidos para produções em climas quentes (Yalçin et al., 1997; Silva et al., 2001).
Observou-se efeito de interação $(\mathrm{P}<0,05)$ entre os níveis de lisina e o sexo somente para o ganho de peso, evidenciando um comportamento diferenciado entre frangos machos e fêmeas (Tab. 2). Os níveis de lisina digestível não influenciaram $(\mathrm{P} \geq 0,05)$ o consumo de ração, entretanto houve efeito significativo $(\mathrm{P}<0,01)$ sobre o consumo de lisina, o ganho de peso e a conversão alimentar. Verificou-se que todas as variáveis avaliadas foram influenciadas $(\mathrm{P}<0,05)$ pelo sexo dos frangos e que os machos apresentaram melhores resultados que as fêmeas.

O consumo de lisina aumentou de forma linear crescente, segundo a equação: $\mathrm{CL}=1,138+$ $19,666 \mathrm{~L}\left(\mathrm{R}^{2}=0,80\right)$, e este resultado foi devido somente às crescentes suplementações dela na ração, já que não houve efeito significativo para o consumo de ração.

Justifica-se a inexistência de efeito significativo $(\mathrm{P} \geq 0,05)$ dos níveis de lisina estudados para $\mathrm{O}$ consumo de ração, uma vez que, na formulação da ração, todos os aminoácidos foram fornecidos conforme a exigência mínima dos frangos e incluídos a partir do conteúdo de lisina, sendo mantidas as relações entre os aminoácidos no conceito da proteína ideal. Lana et al. (2005) também não encontraram efeito dos níveis de lisina sobre o consumo de ração de frangos de corte mantidos em ambiente de termoneutralidade. Por outro lado, Nascimento et al. (2009) encontraram efeito dos níveis de lisina sobre o consumo de ração dos frangos da linhagem Isa Label, nos quais observaram uma redução no consumo em função do aumento dos níveis de lisina na ração.

Tabela 2. Resultados obtidos para o consumo de ração (CR), o consumo de lisina (CL), o ganho de peso (GP) e a conversão alimentar (CA) de frangos machos e fêmeas da linhagem Redbro, no período de 22 a 42 dias de idade

\begin{tabular}{|c|c|c|c|c|c|c|c|c|c|c|c|}
\hline \multirow[t]{2}{*}{ Variável } & \multirow[b]{2}{*}{$\mathrm{S}$} & \multicolumn{4}{|c|}{ Lisina digestível $(\mathrm{g} / \mathrm{kg})$} & \multirow[b]{2}{*}{11,07} & \multirow[t]{2}{*}{ Média } & \multirow[b]{2}{*}{$\mathrm{CV}$} & \multicolumn{3}{|c|}{ Probabilidade de $\mathrm{F}$} \\
\hline & & 7,07 & 8,07 & 9,07 & 10,07 & & & & $\mathrm{~L}$ & $\mathrm{~S}$ & $\mathrm{~L} * \mathrm{~S}$ \\
\hline \multirow{2}{*}{$\begin{array}{c}\text { CR } \\
\text { (g/ave) }\end{array}$} & $\mathrm{M}$ & 2267 & 2211 & 2199 & 2238 & 2208 & $2224,60 a$ & \multirow{2}{*}{4,10} & \multirow{2}{*}{0,78} & \multirow{2}{*}{0,01} & \multirow{2}{*}{0,73} \\
\hline & $\mathrm{F}$ & 1978 & 1983 & 2013 & 1949 & 1905 & $1965,60 \mathrm{~b}$ & & & & \\
\hline \multirow{2}{*}{$\begin{array}{c}\mathrm{CL} \\
\text { (g/ave) }\end{array}$} & $\mathrm{M}$ & 16,03 & 17,85 & 19,94 & 22,53 & 24,44 & $20,16 a$ & \multirow[b]{2}{*}{4,12} & \multirow[b]{2}{*}{0,01} & \multirow[b]{2}{*}{0,01} & \multirow[b]{2}{*}{0,31} \\
\hline & $\mathrm{F}$ & 13,98 & 16,00 & 18,26 & 19,62 & 21,09 & $17,79 \mathrm{~b}$ & & & & \\
\hline \multirow{2}{*}{$\begin{array}{c}\text { GP } \\
\text { (g/ave) }\end{array}$} & M & 920 & 998 & 1036 & 1077 & 1041 & $1014,40 \mathrm{a}$ & \multirow{2}{*}{2,57} & \multirow{2}{*}{0,01} & \multirow{2}{*}{0,01} & \multirow{2}{*}{0,05} \\
\hline & $\mathrm{F}$ & 819 & 847 & 892 & 911 & 849 & $863,60 b$ & & & & \\
\hline \multirow{2}{*}{$\begin{array}{l}\text { CA } \\
(\mathrm{g} / \mathrm{g})\end{array}$} & M & 2,464 & 2,217 & 2,124 & 2,078 & 2,120 & $2,201 \mathrm{a}$ & \multirow{2}{*}{3,61} & \multirow{2}{*}{0,01} & \multirow{2}{*}{0,01} & \multirow{2}{*}{0,28} \\
\hline & $\mathrm{F}$ & 2,416 & 2,341 & 2,259 & 2,141 & 2,245 & $2,280 \mathrm{~b}$ & & & & \\
\hline
\end{tabular}

$\mathrm{CV}=$ coeficiente de variação (\%), $\mathrm{S}=$ sexo, $\mathrm{M}=$ macho, $\mathrm{F}=$ fêmea, $\mathrm{L}=$ lisina. 
Para o ganho de peso, após o desdobramento dos fatores, obtiveram-se as equações linear crescente, quadrática e LRP para os frangos machos, sendo: $\mathrm{GP}=0,7219+0,3221 \mathrm{~L}\left(\mathrm{R}^{2}=\right.$ $0,68) ; \mathrm{GP}=-0,5634+3,227 \mathrm{~L}-1,601 \mathrm{~L}^{2}\left(\mathrm{R}^{2}=\right.$ $0,92)$ e $\mathrm{GP}=1,0589-0,5798(0,9358-\mathrm{L})\left(\mathrm{R}^{2}=\right.$ 0,94), respectivamente. As estimativas dos modelos quadrático e LRP são, respectivamente, de 10,08 e 9,36g de lisina digestível $/ \mathrm{kg}$, no entanto, pela intersecção da equação quadrática com o platô do LRP, obtém-se o nível de 9,59g de lisina digestível/kg na ração para melhor resultado de ganho de peso dos frangos machos. $\mathrm{O}$ ganho de peso das aves fêmeas foi ajustado pela equação quadrática $(\mathrm{GP}=-0,4276+2,7891 \mathrm{~L}$ $\left.-1,4699 \mathrm{~L}^{2} ; \mathrm{R}^{2}=0,53\right)$, sendo possível estimar o nível de 9,49 g de lisina digestível/kg.

Ao avaliarem níveis de lisina sobre o ganho de peso de frangos de corte, Costa et al. (2006) indicaram o nível de $11 \mathrm{~g}$ de lisina por $\mathrm{kg}$ de ração, sendo esse valor mais elevado do que os encontrados neste trabalho, podendo revelar maior exigência de lisina para linhagens de crescimento rápido em relação às linhagens de crescimento lento (tipo caipiras). Barboza et al. (2000) obtiveram melhores resultados de ganho de peso, com os níveis de 9,8 e 9,2g de lisina digestível/kg na ração, para machos das linhagens Ross e Hubbard, respectivamente, e $9,8 \mathrm{~g} / \mathrm{kg}$ para as fêmeas Ross e Hubbard.

A conversão alimentar foi influenciada $(\mathrm{P}<0,01)$ pelos níveis de lisina da ração, de forma linear decrescente, quadrática e pelo modelo LRP, obtendo-se as equações, respectivamente: $\mathrm{CA}=$ $2,8632-0,6865 \mathrm{~L}\left(\mathrm{R}^{2}=0,47\right) ; \mathrm{CA}=5,577$ $6,819 \mathrm{~L}+3,3807 \mathrm{~L}^{2}\left(\mathrm{R}^{2}=0,63\right)$ com estimativa de $10,08 \mathrm{~g} / \mathrm{kg}$ e $\mathrm{CA}=2,1458-1,2448$ (L - 0,9339); $\mathrm{R}^{2}=0,94$, com o nível de $9,34 \mathrm{~g}$ de lisina/kg de ração. Pela primeira intersecção da reta ascendente com o platô, obtém-se o nível de $9,61 \mathrm{~g}$ de lisina digestível $/ \mathrm{kg}$, que minimiza a conversão alimentar dos frangos de ambos os sexos. Os autores Bernal et al. (2014) verificaram efeito quadrático dos níveis de lisina digestível para os frangos machos (linhagem Cobb 500) no período de 22 a 35 dias de idade e estimaram $10,7 \mathrm{~g} / \mathrm{kg}$ e, para as fêmeas, observaram efeito linear, sendo calculado o nível de $11,6 \mathrm{~g} / \mathrm{kg}$ de lisina digestível na ração. Pelo exposto, verificam-se estimativas de níveis de lisina digestível diferentes dos observados no presente estudo, não sendo adequadas, portanto, extrapolações dos níveis de aminoácidos (lisina) entre as diferentes linhagens de frangos de corte.

\section{CONCLUSÃO}

Os frangos machos e fêmeas, tipo caipira, da linhagem Redbro em fase de crescimento (22 a 42 dias de idade), necessitam de 10,08 e 9,49g de lisina digestível/kg de ração, respectivamente, para melhor ganho de peso, correspondendo ao consumo estimado de 21 e $20 \mathrm{~g}$ de lisina, respectivamente. Para melhor conversão alimentar, recomendam-se 9,61g de lisina digestível/kg, para frangos de ambos os sexos, correspondendo ao consumo estimado de $20 \mathrm{~g}$ de lisina.

\section{AGRADECIMENTOS}

Os autores agradecem à Fundação de Amparo à Pesquisa do Estado de Minas Gerais (Fapemig), pelo apoio financeiro; à Ajinomoto Ltda., pela doação dos aminoácidos; e ao Adalfredo Rocha Lobo Júnior, pelo suporte nas análises estatísticas.

\section{COMITÊ DE ÉTICA E BIOSSEGURANÇA}

Este experimento foi aprovado pelo Comitê de Ética em Uso de Animais da Universidade Federal dos Vales do Jequitinhonha e Mucuri, Diamantina, MG, Brasil, sob número de protocolo: 003/2012.

\section{REFERÊNCIAS}

ALBINO, L.F.T; VARGAS Jr., J.G.; SILVA, J.H.V. Criação de frango e galinha caipira: avicultura alternativa. Viçosa: Aprenda Fácil, 2001. 110p.

BARBOZA, W.A.; ROSTAGNO, H.S.; ALBINO, L.F.T.; RODRGUES, P.B. Níveis de lisina para frangos de corte de 1 a 21 e 15 a 40 dias de idade. Rev. Bras. Zootec., v.29, p.10821090, 2000.

BERNAL, L.E.P; TAVERNARI, F.C.; ROSTAGNO, H.S.; ALBINO, L.F.T. Digestible lysine requeriments of broilers. Rev. Bras. Cienc. Avic., v.16, p.49-55, 2014. 
CONHALATO, G.S. Exigência de lisina digestível para frangos de corte machos. 1998. 79f. Dissertação (Mestrado em Zootecnia) Universidade Federal de Viçosa, Viçosa.

COSTA, F.G.P.; AMARANTE Jr., V.S.; NASCIMENTO, G.A.J. et al. Níveis de lisina para frangos de corte nos períodos de 22 a 42 e de 43 a 49 dias de idade. Ciênc. Agrotecnol., v.30, p.759-766, 2006.

LANA, S.R.V.; OLIVEIRA, R.F.M.; DONZELE, J.L. et al. Níveis de lisina digestível em rações para frangos de corte de 22 a 42 dias de idade. Rev. Bras. Zootec., v.34, p.1624-1632, 2005 .

NASCIMENTO, D.C.N.; SAKOMURA, N.K.; SIQUEIRA, J.C. et al. Exigências de lisina digestível para aves de corte da linhagem ISA Label criadas em semiconfinamento. Arq. Bras. Med. Vet. Zootec., v.61, p.1128-1138, 2009.

OLIVEIRA, R.F.M.; DONZELE, J.L.; ABREU, M.L.T. et al. Efeitos da temperatura e da umidade relativa sobre o desempenho e o rendimento de cortes nobres de frangos de corte de 1 a 49 dias de idade. Rev. Bras. Zootec., v.35, p.797-803, 2006.

PINHEIRO, S.R.F.; SAKOMURA, N.K.; NASCIMENTO, D.C.N. et al. Níveis nutricionais de fósforo disponível para aves de corte ISA Label criadas em semiconfinamento. Rev. Bras. Zootec., v.40, p.361-369, 2011 a.
PINHEIRO, S.R.F.; SAKOMURA, N.K.; SIQUEIRA, J.C. et al. Níveis nutricionais de cálcio para aves de corte ISA Label criadas sob semiconfinamento. Arq. Bras. Med. Vet. Zootec., v.63, p.231-238, 2011 b.

ROSTAGNO, H.S.; ALBINO, L.F.T.; DONZELE, J.L. et al. Tabelas brasileiras para aves e suínos: composição de alimentos e exigências nutricionais. Viçosa, MG: Universidade Federal de Viçosa, 2011.

SAKOMURA, N.K.; ROSTAGNO, H.S. Métodos de pesquisa em nutrição de monogástricos. Jaboticabal, SP: FUNEP, 2007. $283 \mathrm{p}$.

STATISTICAL analysis system: user's guide statistics. Version 9.2. Cary, NG: SAS Inst., 2008.-+

SILVA, M.A.N.; SILVA, I.J.O.; PIEDADE, S.M.S. et al. Resistência ao estresse calórico em frangos de corte de pescoço pelado. Rev. Bras. Cienc. Avíc., v.3, p.27-33, 2001.

YALÇIN, S.; TESTIK, A.; OZKAN, S. et al. Performance of naked neck and normal broilers in hot, warm, and temperate climates. Poultry Science, v.76, p.930-937, 1997. 